\title{
ЧЕЛОВЕЧЕСКИЙ МИАЗ: КЛИНИЧЕСКИЙ СЛУЧАЙ
}

\section{ОРИГИНАЛЬНАЯ СТАТЬЯ}

SILVA, Agnaldo Plácido da ${ }^{1}$, PLÁCIDO, Eloá Jessica Mendes dos Santos² MORAES, Walber Breno de Souza ${ }^{3}$

SILVA, Agnaldo Plácido da. PLÁCIDO, Eloá Jessica Mendes dos Santos. MORAES, Walber Breno de Souza. Человеческий миаз: Клинический случай. Revista Científica Multidisciplinar Núcleo do Conhecimento. 05-й год, Эд. 08, Vol. 10, стр. 39-46. Август 2020 года. ISSN: 2448-0959, Ссылка доступа: https://www.nucleodoconhecimento.com.br/здравоохранение/человеческий-миаз, DOI: 10.32749/nucleodoconhecimento.com.br/ru/61099

\section{PEЗЮME}

Миаз считается дерматозунозом заражения, вызванного заражением личинок диттерана в тканях или органах, которые откладывают яйца у людей или животных, которые в течение определенного периода питаются живыми или мертвыми тканями хозяина, возникновение миаза в полости рта можно считать редкостью. Этот тип заболевания чаще всего поражает людей с низким социально-экономическим статусом, ослабленным иммунитетом, прикованным к постели пожилым людям и с психическими расстройствами. Из-за своего большого разрушительного потенциала, своевременной и важной соответствующей профилактики и лечения, есть также мало знаний о стоматолога для диагностики и лечения такой патологии, По этой причине,

\footnotetext{
${ }^{1}$ Докторант биомедицинских наук в IUNIR - Instituto Universitário Italiano de Rosario - Аргентина. Специалист по челюстно-лицевой хирургии и травматологии в комплексной стоматологической клинике Ciodonto. Окончила стоматологическую ассоциацию ASCES - Ассоциация высшего образования Caruaruense. Получила диплом биолога в Университете Pernambuco (UPE).

2 Окончил курс физиотерапии колледжа UNINASSAU.

${ }^{3}$ Степень по биологии UPE- Университет Pernambuco. Магистр природных ресурсов - UFCG. Профессор УНОПАР.
}

RC: 61099

Disponível

em: https://www.nucleodoconhecimento.com.br/здравоохранение/человеческий- 
настоящее исследование сообщает клинический случай орального миоза в пожилом человеке прикован к постели с историей злокачественных ларингальной / глоттальной неоплазии травмы, представляя фризическую и психическую слабость и неадекватную гигиену тела и отсутствие липовых уплотнения, что привело к Диагноз был клинически установлен на основе наблюдения за кровотечением языка, отслоением тканей и наличием личинок, которые находились между второй и третьей стадиями развития. Лечение было начато как госпитализация пациента для дебридирования некротических тканей и удаления личинок и рецепта ивермектина. Прикованные к постели пациенты с фризической и металлической слабостью составляют группу риска для орального миоза, и очень важно направлять воспитателей и членов семьи в отношении стоматологической помощи, чтобы предотвратить эту патологию. Однако отсутствие консенсуса по наилучшему терапевтическому подходу к случаям орального миоза было принято в качестве терапевтического поведения при заболевании механического удаления личинок и института перорального применения ивермектина.

Ключевые слова: Ларва, человеческий миаз, мухи, общественное здравоохранение.

\section{1. ВВЕДЕНИЕ}

Миоз определяется как патология, при которой происходит мор личинок мух, питаются живыми или мертвыми тканями (VINIT; JAYAVELU и SHRUTHA, 2013), хотя этот паразитоз был описан в течение многих лет исследователями, технический термин для названия бичейра был предложен в 1840 году преподобным F. W. Норе в своей работе « On insects and their larvae occasionally found in the human body », где предлагается использовать термин «миаз», который происходит от греческих слов myia (муха) и ase (болезнь) (GUIMARAES; PAPAVERO и PRADO, 1983). В индуистской литературе миаз

RC: 61099

Disponível

em: https://www.nucleodoconhecimento.com.br/здравоохранение/человеческиймиаз 
считался мифологией наказанием грешников (PARMAR; DAVESSAR et al., 2018).

Пациенты с миозом обычно представляют некоторые фракторы, которые приводят к предрасположенности к их развитию, такие как умственная отсталость, психические расстройства, старость, сосудистые заболевания, неоплазмы, диабет и иммунодепрессия и хроническое потребление алкоголя, и происходит предпочтительно у пожилых людей. (MARQUEZ; MATTOS и NASCIMENTO, 2007) (SILVEIRA; PINHEIRO et al., 2015) Однако, фракторы наибольшей актуальности для начала миаза по-прежнему возникновение открытых поражений с экссудациями и плохой тела и гигиены полости рта (NASCIMENTO; OLIVEIRA et al., 2005) (TOURÉ, 1994).

Это ситуация смертельной тяжести для пациента, в дополнение к причинению боли и разрушения тканей. Устные миаз может представлять как рваная рана полости рта, отек слизистой оболочки рта, воспаление десен (RIBEIRO; PEREIRA et al., 2001). « В случае полостной миаз, которая включает в себя области рта и носа и параназальной пазухи, можно утверждать, что это очень редкий тип миаза » (BARNABÉ; FERRAZ et al., 2016). Наиболее распространенным разнообразием видов мух, ответственных за большинство случаев миаза включает Cochliomyia hominivorax, Chrysomya bezziana, Oestrus ovis, Великолепный Wohlfahrtia и отечественную Муску. Заболеваемость инфекцией встречается редко даже в развивающихся странах (KHAN; SABIR et al., 2018) (TOURÉ, 1994).

Лечение миаза в основном состоит из ручного удаления личинок с помощью кюретки и клинического пинцета, обычно под наркозом или обезболивающим, в зависимости от клинического состояния пациента, удаление личинок должно выполняться осторожно, чтобы личинки не фрагментируются, и их остатки остаются на месте, вызывая инфекционный процесс (CAVALCANTI, 2008), хотя

RC: 61099

Disponível

em: https://www.nucleodoconhecimento.com.br/здравоохранение/человеческиймиаз 
на рынке есть некоторые продукты, которые можно использовать для облегчения удаления (BARNABÉ; FERRAZ et al., 2016), литература с большим успехом сообщает о системном применении дозы ивермектина, полусинтетического макролидного антибиотика для лечения более тяжелых случаев, связанных с наличием миаза полости рта, что оказалось безопасным методом при рекомендуемых дозах 200 мкг / кг. Даже при дозах 300 или 400 мкг / кг пациенты, проходящие лечение, не проявляли каких-либо серьезных клинических побочных эффректов, за исключением легкого зуда (GEALH; FERREIRA et al., 2009) (RIBEIRO; PEREIRA et al., 2001).

Мы можем разделить миаз на три различных типа: бионофагальный или первичный, то есть те личинки двукрылых, которые развиваются на позвоночных или внутри них, питаясь живыми тканями хозяина. Среди этих видов мы можем найти Cochliomy homini vorax и Dermatobia hominis. Вторичные некробионтофоры - это те, у которых личинки двукрылых развиваются в органическом веществе, которое уже разлагается (трупы), действуя как сапрофраги, но также могут поражать некротические ткани живого хозяина. Самые распространенные жанры: Lucília, Phaenicia, Musca и Fannia. Псевдомиаз (случайный): это может произойти из-за проглатывания яиц и / или личинок двукрылых, присутствующих в зараженной пище, попавшей в организм хозяина, что вызывает расстройство кишечника (CAVALCANTI, 2008) (BOROS; BOROS et al., 2006).

\section{2. КЛИНИЧЕСКИЙ СЛУЧАЙ}

69-летний пациент мужского пола с диагнозом злокачественной неоплазмы в языке (проходит химиотерапию) был госпитализирован в отделение неотложной помощи Dom Moura областной больницы в Garanhuns Pernambuco жалуются на боль и нечастый квентинг в области рта в течение нескольких недель, был направлен в Bucomaxillofacial хирургии и 
травматологии службы. При госпитализации пациент был афебрилом, ориентировался и сотрудничал, кровотечение наблюдалось во рту, учитывая сообщение семьи о том, что у пациента были проблемы с зубами, проводились обследования. В интраоральной оценке показаны четко определенные язвенные поражения с центральной некротической ткани и несколько живых личинок на языке. (Рисунок 1)

Рисунок 1 - Личинки на языке.

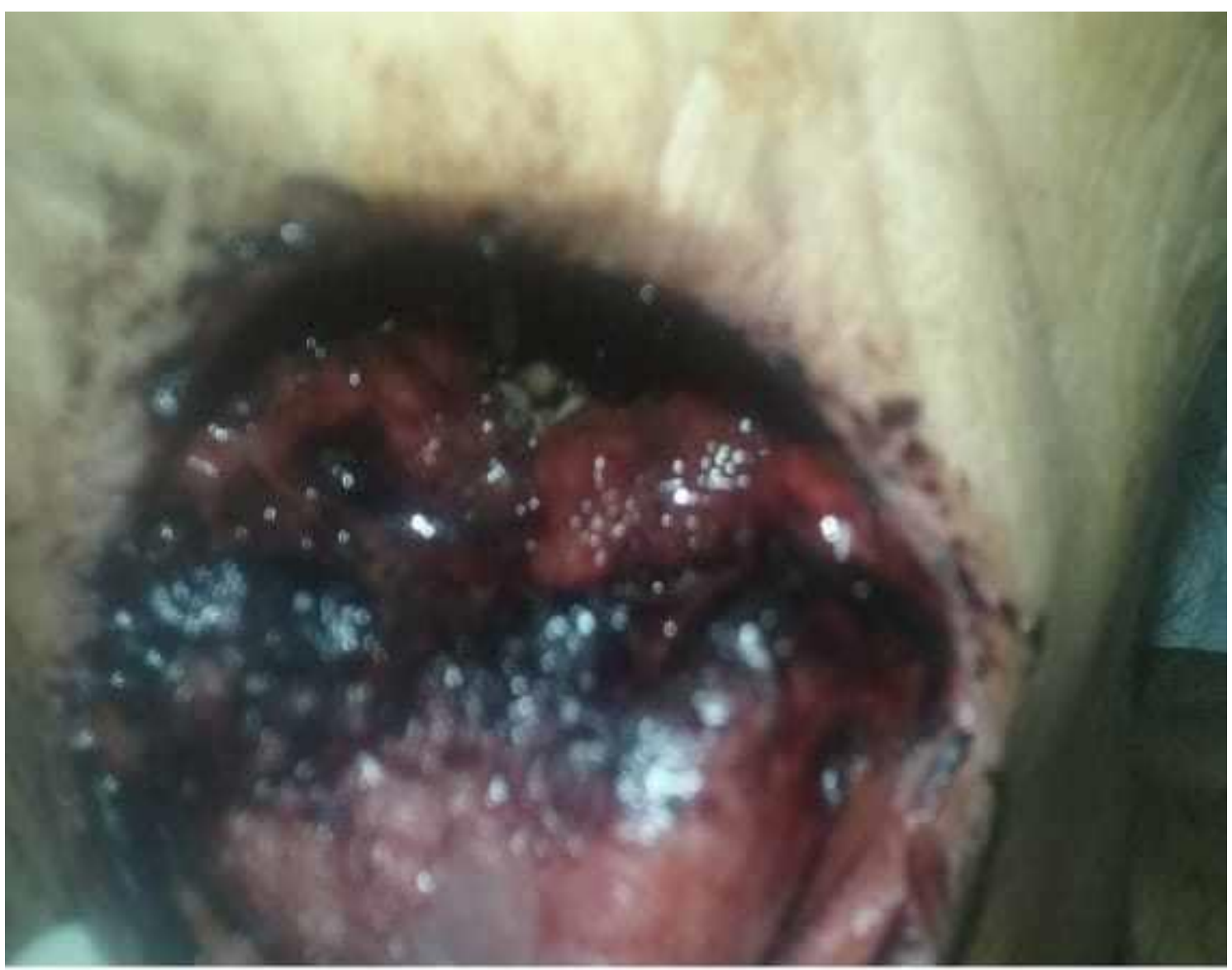

Источник: Авторы (2020).

Пациент, пострадавший от этого заболевания, представил предрасполагающие фракторы, такие как фризическая и психическая слабость, обезвоживание, 
неадекватная гигиена тела, диабет, недоедание, дыхание во рту во время сна и плохое поддержание гигиены полости рта.

Таким образом, было проведено первичное симптоматическое лечение. Рана была очищена и дезинфицирована раствором хлоргексидина 0,12\%. Личинки вручную удаляются под местной анестезией с помощью клинических пинцетов, все асептическое поле, личинки в этом случае были собраны и помещены в клинический лоток. Около 80 личинок были вывезены из региона, и все они не могли быть удалены (рисунок 2).

Рисунок 2 - Личинки удалены из очага поражения

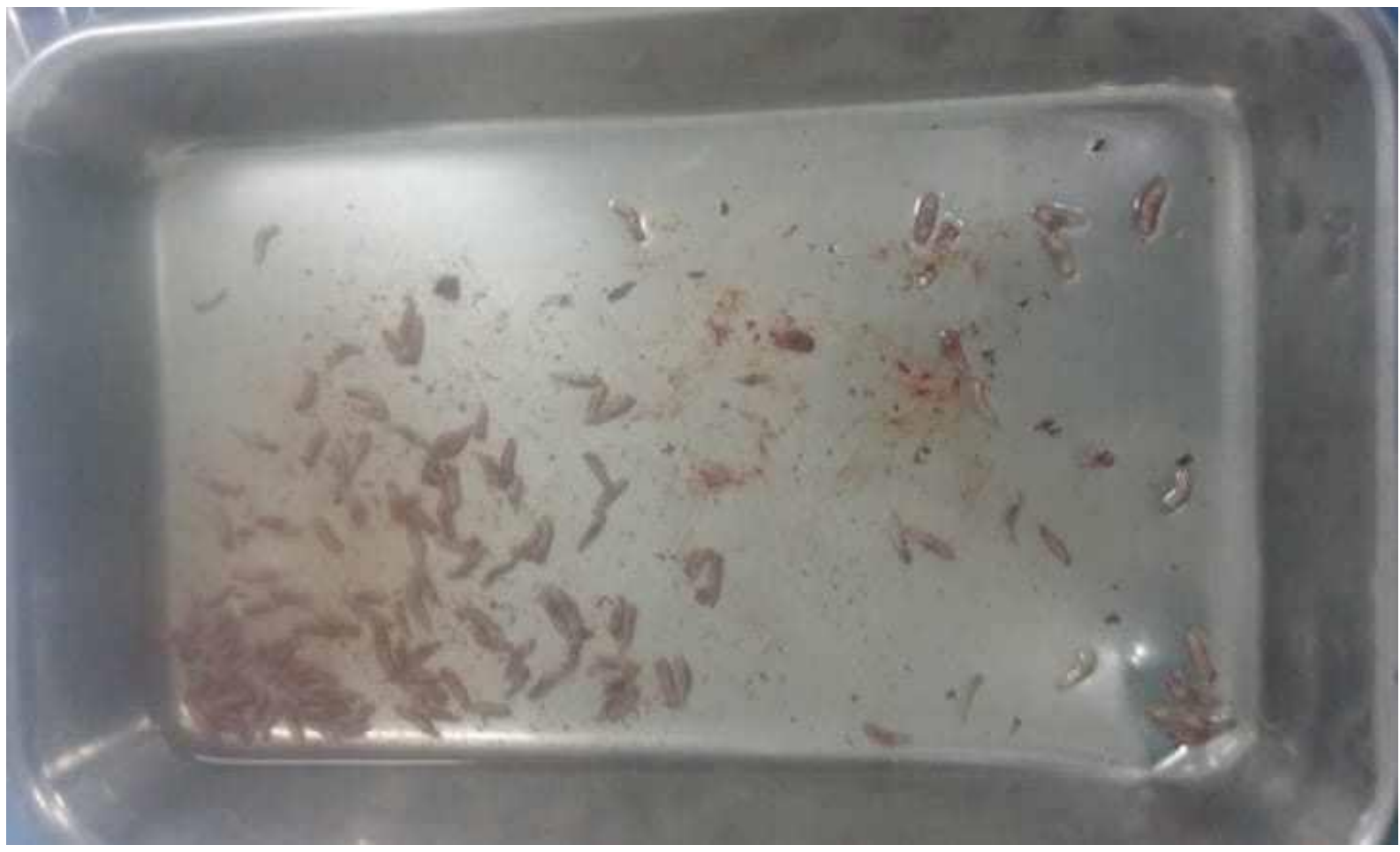

Источник: Авторы (2020).

Пациент был госпитализирован и внутривенно антибиотикотерапия была начата Цефралотин 1г, Дипирона и Кетопрофрен, и одна устная доза Ивермектина две таблетки, т.е. 12 мг (примерно 200 мкг/кг), Через 10 дней все 
оставшиеся личинки были ликвидированы, без необходимости дополнения Ивермектина.

\section{3. ОБСУЖДЕНИЕ}

В процессе развития личинок в соседних тканях присутствует воспалительный процесс, с язвой или без некроза тканей (CARVALHO; SANTOS et al., 2008). Многие серьезные осложнения могут возникнуть из-за миаза: целлюлит, эрозия костей и зубов, бактериемия и смерть (SZAKACS и MACPHERSON, 2007).

Во многих из статей консультации, мы отметили, что авторы отмечают, что устный миаз является редкой патологией, и что диптераны не имеют предпочтения по возрасту, полу и этнической принадлежности. И что заражение личинки диттеров больше в сельской местности, заражая домашних животных, таких как собаки, кошки, свиньи, быки. Общее мнение авторов заключается в том, что люди, которые были заражены личинками, являются умственно отсталыми, люди с небольшим количеством тела и гигиены полости рта, такие как низкий уровень образования, люди с низким социально-экономическим статусом (BOROS; BOROS et al. 2006).

Диагноз миаз человека является клиническим, так что можно обнаружить некоторые из его осложнений может быть необходимо для выполнения компьютерной томографии, УЗИ или магнитно-резонансной томографии (SHENOUDA; ENTEN et al., 2018).

Присутствие личинок на коже вызывает местную воспалительную реакцию с миграцией и распространением воспалительных клеток, таких как нейтрофилов, тучных клеток, эозинофилов, фрибробластов и эндотелиальных клеток. Тем не менее, полный анализ клеток крови может показать высокий уровень лейкоцитов и эозинофилов (PAYNE и COSGROVE, 1966) (SHENOUDA; ENTEN et al., 2018).

RC: 61099

Disponível

em: https://www.nucleodoconhecimento.com.br/здравоохранение/человеческиймиаз 
Некоторые авторы выступают за традиционное лечение миоза, которое включает в себя удаление личинок с помощью химических веществ, которая направлена на содействие асфиксии личинок, вызывающих их выход из поражения. В более крупных поражениях, где он представляет клиническую картину смежного целлюлита, дебридирование местных тканей будет указано с удалением некротических тканей, но другие защищают как идеал, хирургическое лечение, которое позволяет удалить все личинки в союзе с дебридированием, и антибиотики для предотвращения вторичной инфекции, другой метод уже был опробован в качестве использования одной дозы ивермектина (PARMAR; DAVESSAR et al., 2018).

Миаз можно рассматривать как проблему общественного здравоохранения, которую можно предотвратить путем устранения факторов риска для здоровья человека, таких, как отсутствие элементарных санитарных условий и недостаточное удаление мусора, где подвергается воздействию органический материал, который привлекает насекомых и мелких животных, создавая устойчивый цикл грязи. Плохая санитария, вероятно, является наиболее важным фрактором риска развития миаза человека (FRANCESCONI и LUPI, 2012).

\section{4. ЗАКЛЮЧЕНИЕ}

В литературе было предложено несколько методов лечения политарного миоза, начиная от механической экстракции и до использования актуальных, пероральных и внутривенных веществ. Но ранняя и правильная диагностика позволяет лечение с благоприятным прогнозом. Однако, независимо от используемых средств, важно, чтобы пациент был ориентирован на принятие соответствующих мер личной гигиены. Тем не менее, нет консенсуса по поводу наилучшего терапевтического подхода для случаев орального миоза.

\section{5. ИСПОЛЬЗОВАННАЯ ЛИТЕРАТУРА}

RC: 61099

Disponível

em: https://www.nucleodoconhecimento.com.br/здравоохранение/человеческий- 
BARNABÉ, A. S. et al. Epidemiologia Da Miíase Cutânea: Revisão Da Literatura. Atas de Ciências da Saúde, São Paulo, v. 4, n. 2, p. 14-22, Abril - Junho 2016.

BOROS, L. F. et al. Míase Labial. Revista Dens, v. 14, n. 1, p. 1-10, Revista Dens, v.14, n.1, maio/outubro 20062006.

CARVALHO, R. W. F. et al. Oral and maxillofacial myiasis associated with epidermoid carcinoma: a case report. Journal of Oral Science, v. 50, n. 1, p. 103-105, 2008

CAVALCANTI, A. L. Miíase Oral: etiologia, diagnóstico e tratamento. Rev. Fac. Odontol. Porto Alegre, Porto Alegre, v. 49, n. 2, p. 32-35, maio/ago. 2008.

CAVALCANTI, A. L. Mí́ase Oral: etiologia, diagnóstico e tratamento. Rev. Fac. Odontol. Porto Alegre, Porto Alegre, v. 46, n. 2, p. 32-35, maio/ago. 2008.

FRANCESCONI, ; LUPI,. Myiasis. Clinical Microbiology Reviews , v. 25, n. 1, p. 79 105, Jan. 2012

GEALH, W. C. et al. Treatment of oral myiasis caused by Cochliomyia hominivorax: two cases treated with ivermectin. British journal of Oral and Maxillofacial Surgeons, v. 47, n. 1, p. 23-26, January 2009.

GUIMARAES, J. H.; PAPAVERO, ; PRADO, A. P. D. As Mi1ases Na Região Neotropical. Revista Brasileira De Zoologia (Identificação, Biologia, Bibliografia), São Paulo, v. 1, n. 4, p. 239.416, 1983.

KHAN, B. A. et al. Oral and cutaneous myiasis in a 5 year old child from Karachi, Pakistan. Le Infezioni in Medicina, v. 4, p. 385-388, 2018.

MARQUEZ, A. T.; MATTOS, M. D. S.; NASCIMENTO, S. B. Míases associadas com alguns fatores sócio-econômicos em cinco áreas urbanas do Estado do Rio de 
Janeiro. Revista da Sociedade Brasileira de Medicina Tropical, v. 40, n. 2, p. 175180, março - abril 2007.

NASCIMENTO, E. M. F. D. et al. Miíases Humanas Por Cochliomyia Hominivorax (Coquerel, 1858) (Diptera, Calliphoridae) Em Hospitais Públicos Na Cidade Do Recife, Pernambuco, Brasil. Entomología y Vectores, v. 12, n. 1, p. 37-51, 2005.

PARMAR, S. et al. Tracheostomal Myiasis: A Case Report And Review Of Literature. International Journal of Scientific Research, v. 7, n. 12, p. 4-6, December 2018.

PAYNE, J. A.; COSGROVE, G. E. Tissue changes following Cuterebra infestation in rodents. The American Midland Naturalist, v. 75, n. 1, p. 205-213, Jan. 1966.

RIBEIRO, F. A. Q. et al. Tratamento da miíase humana cavitária com ivermectina oral. Rev Bras Otorrinolaringol, v. 67, n. 6, p. 755-761, nov./dez. 2001.

SHENOUDA, M. et al. Human Botfly: A Case Report and Overview of Differential Diagnosis. J Investig Med High Impact Case Rep., v. 6, Jan-Dec; 2018.

SILVEIRA, M. A. A. et al. Cavitary myiasis mimicking peritonsilar abscess. Brazilian Journal of Otorhinolaryngology, v. 81, p. 336-338, 2015.

SZAKACS, T. A.; MACPHERSON,. Nosocomial myiasis in a Canadian intensive care unit. CMAJ, v. 177, n. 7, p. 719-720, 25 September 2007.

TOURÉ, S. M. Les myiases d'importance économique. Rev. sci. tech. Off. int. Epiz., 1994, 13 (4), 1053-1073, v. 13, n. 4, p. 1053-1073, 1994.

VINIT, G. B. ; JAYAVELU, P.; SHRUTHA, S. P. Oral myiasis in a maxillofacial trauma patient. J Pharm Bioallied Sci., v. 5, n. 6, p. 195-197, 5 Jul 2013.

Отправлено: февраль 2020 года.

RC: 61099

Disponível

em: https://www.nucleodoconhecimento.com.br/здравоохранение/человеческий- 
Утверждено: Август 2020 года.

RC: 61099

Disponível

em: https://www.nucleodoconhecimento.com.br/здравоохранение/человеческиймиаз 